\title{
Analisis Pengendalian Kualitas Produk Pengalengan Ikan Dengan Metode Statistical Quality Control (Studi Kasus: Pada CV. Pasific Harvest)
}

\author{
Melinda Anggita Putri ${ }^{1}$, Cheryll Chameloza ${ }^{2}$, Rista Anggriani ${ }^{*}$ \\ 1Program Studi Teknologi Pangan, Fakultas Pertanian-Peternakan, Universitas Muhammadiyah \\ Malang, Malang Indonesia. \\ ${ }^{2}$ Quality Assurance Departement, CV. Pasific Harvest, Banyuwangi, Indonesia \\ *Corresponding author email: rista@umm.ac.id
}

\begin{abstract}
Canning fish is a processed fish product that has gone through a processing stage, packaged in cans and given heat to ripen fish and other fillings and kill spoilage microbes. During the fish canning process there is product damage caused by several factors such as the production process that is not in accordance with the procedures, poor machinery and equipment, and unsupportive environmental conditions. One of the main causes of damage to fish canning products is cans damage which results in products being contaminated with microbes so that the contents of the cans will experience changes in color, taste and odor. Product damage needs to be minimized by carrying out quality control. Product quality is the most important aspect for companies to survive in the midst of competition between companies. One of the efforts that can be used to maintain product quality is the Statistical Quality Control method. This method can be used to analyze, manage and improve nonstandard processes using a statistical approach. SQC has the ability to describe process abnormalities, see the pattern of increasing/decreasing processes in the process, so that corrective action can be taken and even preventive action before the problem actually occurs. The purpose of this study was to determine the quality of fish canning products from the level of product damage using the Statistical Quality Control method and to determine the causes of damage to fish canning products. The study was conducted using the Statistical Quality Control method with the stages of making a check sheet, histogram, control chart, and finally making a causal diagram to determine the cause of product damage. Based on the results of the analysis of calculations using the control chart for 26 days of observation, it is known that there is still damage that is outside the upper control limit which indicates a deviation and based on the analysis of the causal diagram of the factors that cause deviations, namely machines, materials, methods, humans and the environment.
\end{abstract}

Keywords: Cause and Effect Diagram, Control Chart, Deviation, Product Damage

\begin{abstract}
Abstrak. Pengalengan ikan merupakan produk olahan ikan yang telah melalui tahap pemrosesan, dikemas dalam kaleng dan diberi panas untuk mematangkan ikan dan isian lainnya serta membunuh mikroba pembusuk. Pada saat proses pengalengan ikan terdapat kerusakan produk yang disebabkan oleh beberapa faktor seperti proses produksi yang tidak sesuai dengan prosedur, mesin dan peralatan yang kurang baik, serta kondisi lingkungan yang tidak mendukung. Salah satu penyebab kerusakan produk pengalengan ikan yang utama yaitu kerusakan kaleng yang mengakibatkan produk terkontaminasi dengan mikroba sehingga isi kaleng akan mengalami peruabahan warna, rasa dan bau yang tidak sedap. Kerusakan produk perlu diminimalisir dengan melakukan pengendalian kualitas. Kualitas produk merupakan aspek terpenting bagi perusahaan agar tetap bertahan di tengah
\end{abstract}


persaingan antar perusahaan. Salah satu upaya yang dapat digunakan untuk menjaga kualitas produk yaitu dengan metode Statistical Quality Control. Metode ini dapat digunakan untuk menganalisis, mengelola dan memperbaiki proses-proses yang tidak sesuai standar dengan menggunakan pendekatan statistika. SQC mempunyai kemampuan menggambarkan ketidaknormalan proses, melihat pola kecenderungan peningkatan/ penurunan proses, sehingga bisa diambil tindakan perbaikan bahkan tindakan pencegahan sebelum masalah tersebut benar-benar terjadi. Tujuan dari penelitian ini yaitu untuk mengetahui kualitas produk pengalengan ikan dari tingkat kerusakan produk dengan metode Statistical Quality Control serta untuk mengetahui penyebab dari kerusakan produk pengalengan ikan. Penelitian dilakukan menggunakan metode Statistical Quality Control dengan tahapan pembuatan check sheet, histogram, peta kendali, dan terakhir pembuatan diagram sebab akibat untuk mengetahui penyebab kerusakan produk. Berdasarkan hasil analisa dari perhitungan menggunakan peta kendali $\mathrm{p}$ selama 26 hari pengamatan, diketahui masih terdapat kerusakan yang berada diluar batas kendali atas yang menunjukkan adanya penyimpangan dan berdasarkan dari analisa diagram sebab akibat faktor yang menyebabkan penyimpangan yaitu mesin, material, metode, manusia dan lingkungan.

Kata Kunci: Diagram Sebab Akibat, Kerusakan Produk, Penyimpangan, Peta Kendali

\section{PENDAHULUAN}

Pengalengan ikan merupakan produk olahan ikan yang telah melalui pemrosesan, dikemas dalam kaleng serta diberi panas untuk mematangkan dan membunuh mikroba. Mutu pengalengan ikan tergantung pada kesegaran bahan baku, cara pengalengangan, peralatan, dan kecakapan serta pengetahuan pelaksana teknis, sanitasi dan hygeni pabrik beserta lingkungannya. Kerusakan pada produk kaleng meliputi kerusakan kimia, mikrobiologis, dan pengkaratan (korosi) dan imteraksi antara produk dengan bahan pembuat kaleng yang dapat meyebabkan perubahan yang tidak diinginkan. Pada dasarnya kerusakan utama pada makanan kaleng ditimbulkan oleh kurang sempurnanya proses termal dan pencemaran kembali sesudah pengolahan, yang dapat disebabkan oleh tiga hal yaitu keadaan terlipatnya sambungan-sambungan kaleng, kontaminasi bakteriologis dari air pencuci atau air pendingin, serta peralatan kerja yang kurang baik. Kerusakan-kerusakan tersebut seperti perubahan warna, kerusakan karena sulfida, flat sours, dan penggembungan kaleng (Wulandari et al, 2009).

Banyak perusahaan yang bergerak di bidang pengalengan ikan dengan persaingan yang sangat ketat, perusahaan dituntut untuk terus menjaga kualitas produknya supaya tingkat keberhasilan dari proses produksi dapat terpenuhi dan produk dapat bersaing di pasar. Kualitas suatu produk sangat menentukan produk tersebut telah memenuhi standar yang telah ditetapkan atau tidak sesuai dengan standar. Menurut Anggraeni et al (2016) kualitas produk merupakan kemampuan suatu produk dalam melaksanakan fungsi dan kinerjanya yang dapat memenuhi kebutuhan dan keinginan. Kualitas produk menjadi hal penting yang harus dimiliki oleh sebuah produk, sehingga produsen dituntut untuk menghasilkan produk yang berkualitas agar dapat menarik perhatian konsumen 
dan memenangkan pasar. Untuk menjaga kualitas produk tetap terjaga perlu dilakukan pengendalian kualitas. Pengendalian kualitas digunakan untuk mengimbangi tuntutan persaingan yang semakin ketat serta mengurangi kerugian dari segi biaya yang disebabkan oleh produk yang tidak sesuai dengan spesifikasi. Tujuan dari pengendalian kualitas adalah adalah agar produk hasil produksi dapat mencapai standar kualitas yang telah ditetapkan (Darsono, 2013). Pengendalian kualitas dapat dilakukan dengan beberapa cara salah satunya dengan metode Statistical Quality Control.

Statistical Quality Control merupakan metode pengendalian kualitas dengan cara pendekatan secara statistika. Metode ini digunakan untuk memastikan setiap proses yang digunakan berjalan secara optimal, sehingga produk yang dikirimkan kepada konsumen memenuhi standar kualitas. Menurut Hairiyah et al (2019) Statistical Quality Control merupakan teknik penyelesaian suatu masalah yang digunakan untuk mengamati, mengendalikan, menganalisis, mengelola dan memperbaiki produk menggunakan metode statistik sehingga diharapkan dapat memberikan upaya untuk meningkatkan kualitas produk dan memperluas pasar. Dengan atau tanpa SQC, risiko selama produk tetap ada namun dapat diminimalisir setelah mengetahui penyebab penyimpangannya. Tujuan dari SQC adalah untuk menunjukkan tingkat reliabilitas sampel dan bagaimana cara mengawasi risiko. Kelebihan dari metode SQC adalah bekerja berdasarkan data/fakta yang obyektif dan bukan berdasarkan opini yang subyektif. SQC mempunyai kemampuan menggambarkan ketidaknormalan proses, melihat pola kecenderungan peningkatan/ penurunan proses, sehingga bisa diambil tindakan perbaikan bahkan tindakan pencegahan sebelum masalah tersebut benar-benar terjadi. SQC bisa langsung efektif bekerja pada area dimana suatu proses produksi itu berlangsung sehingga penyimpangan produk dapat dicegah sedini mungkin (Rusdianto et al, 2016).

Menurut Hairiyah et al (2020) alat-alat statistik yang digunakan dalam metode Statistiqal Quality Control untuk pengendalian kualitas yaitu Check Sheet yang berfungsi untuk memperoleh angka kecacatan yang disajikan dalam formulir, Fishbone Diagram digunakan untuk mengidentifikasi berbagai sebab dari suatu masalah, Histogram berfungsi untuk menyajikan data secara grafis serta membuat rangkuman data sehingga data mudah dianalisis, dan Control Chart merupakan alat yang digunakan untuk memonitor dan mengevaluasi adanya perubahan data dari waktu ke waktu tetapi juga menunjukkan penyebab penyimpangan. Penelitan menggunakan metode Statistical Quality Control telah dilakukan sebelumnya oleh Rusdianto et al (2016) yang melakukan penelitian tentang penerapan SQC pada pengolahan kopi robusta cara semi basah, hasil penelitian dengan metode SQC peneliti dapat mengetahui bahwa terdapat penyimpangan pada proses pengolahan kopi robusta sehingga dilakukan 
pengendalian untuk menghilangkan atau meminimalisir penyimpangan tersebut untuk menghasilkan kopi robusta dengan kualitas baik.

Industri pengalengan ikan setiap harinya masih mendapati adanya produk cacat. Kerusakan produk tersebut disebabkan dari beberapa proses mulai dari proses penerimaan bahan baku sampai produk akhir. Kerusakan pada produk pengalengan ikan menurut Adawiyah (2008) dibagi menjadi kerusakan yang disebabkan karena kesalahan pengolahan dan kebocoran kaleng. Maka dari itu perlu dilakukannya analisis mengenai upaya pengendalian kualitas dan mencarinya sebab masih terjadinya kerusakan produk menggunakan metode Statistical Quality Control. Tujuan dari penelitian ini yaitu untuk mengetahui kualitas produk pengalengan ikan dari tingkat kerusakan produk dengan metode Statistical Quality Control serta untuk mengetahui penyebab dari kerusakan produk pengalengan ikan

\section{METODE PENELITIAN}

Alat

Alat yang digunakan dalam penelitian adalah perangkat lunak untuk mengolah data berupa Microsoft Excel dan alat hitung.

\section{Bahan}

Bahan yang digunakan berupa data primer yang diperoleh peneliti di CV. Pasific Harvest Banyuwangi dengan cara observasi dan wawancara serta data sekunder yang diperoleh dari jurnal, buku dan internet yang berkaitan dengan topik yang diteliti. Menurut Oktaviani (2015) data primer yaitu data yang diperoleh peneliti secara langsung dengan maksud khusus untuk menyelesaikan permasalahan yang sedang ditanganinya. Data primer ini merupakan data yang sifatnya terbarukan yang diperoleh langsung dari subyek penelitian. Data primer yang digunakan berupa hasil tinjauan langsung dari sumber yang diamati. Data ini dapat diperoleh dengan cara observasi, yaitu dengan cara pengamatan dan pencatatan langsung terhadap obyek yang diteliti. Selain pengamatan langsung wawancara dengan pihak yang berhak atau berwenang mengenai obyek yang diteliti juga dapat dilakukan untuk memperoleh data primer. Sedangkan untuk data sekunder dapat diperoleh dari hasil penelitian sebelumnya dan mempunyai kaitannya dengan objek yang akan diteliti, untuk memperoleh data sekunder dapat dilakukan riset kepustakaan atau metode pengumpulan data yang dilakukan dengan cara mengambil bahan-bahan dari buku, jurnal, ebook atau literatur lainnya yang berikatan dengan objek yang diteliti. Data sekunder juga dapat diperoleh berdasarkan penelusuran data pada instansi terkait. Data sekunder adalah data yang dikumpulkan lebih dulu dan dilaporkan oleh orang diluar dari penyidik sendiri, meskipun data yang dikumpulkan itu adalah data yang asli (Sugiarto dan Siagian, 2000). 


\section{Prosedur Penelitian}

Adapun teknik analisis data yang digunakan dalam penelitian ini dengan menggunakan metode seven tools mengikut metode Idris et al (2016) adalah sebagai berikut data kecacatan dengan Check Sheet, histogram, membuat control chart, dan menganalisa penyebab dengan fishbone.

Langkah-langkah yang perlu dilakukan yaitu: (Zecky, 2018)

1. Penyusunan Lembar Pengecekan

Data dari penelitian yang telah dikumpulkan diolah dalam bentuk tabel secara rapi dan terstruktur dengan menggunakan check sheet.

2. Penyusunan Histogram

Agar mudah dalam membaca dan menjelaskan data dengan cepat, maka data tersebut perlu untuk disajikan dalam bentuk histogram yang berupa alat penyajian data secara visual berbentuk balok yang memperlihatkan distribusi nilai yang diperoleh dalam bentuk angka.

3. Penyusunan Peta Kendali

Dalam penelitian ini digunakan peta kendali $\mathrm{P}$ (peta kendali proporsi kerusakan) sebagai alat untuk menganalisa pengendalian kualitas secara statistika. Untuk mendapatkan bagan peta kendali dilakukan beberapa langkah yaitu, menghitung rata-rata kerusakan produk, menentukan standar deviasi/penyimpangan, menghitung garis pusat / central line (CL), menghitung batas kendali, dan yang terakhir membuat bagan atau grafik peta kendali $\mathrm{P}$.

4. Penyusunan Diagram Sebab Akibat

Langkah selanjutnya melakukan analisis terhadap faktor penyebab kerusakan. Fishbone diagram merupakan diagram garis yang menggambarkan garis-garis faktor terjadinya cacat produk yang diidentifikasi dari berbagai segi, antara lain manusia, mesin, metode, bahan dan lingkungan.

\section{HASIL DAN PEMBAHASAN}

Statistical Quality Control merupakan suatu teknik statistik yang digunakan secara luas untuk memastikan bahwa proses memenuhi standar. SQC juga digunakan untuk mengawasi standar kualitas produk, membuat pengukuran dan mengambil tindakan perbaikan selama produk sedang diproduksi (Bakhtiar et al, 2013). Adapun langkah-langkah untuk mengetahui permasalahan pengendalian kualitas dengan metode SQC (Statistical Quality Control) sebagai berikut:

\section{Lembar Pengecekan}

Lembar pengecekan merupakan suatu tipe khusus untuk pengumpulan data. Lembar pengecekan (check sheet) mempermudah pengumpulan data, cenderung membuat usaha pengumpulan data lebih akurat, dan secara otomatis menghasilkan semacam ringkasan data yang sangat efektif untuk analisis cepat 
(Hairiyah \& Riyadi, 2017). Adapun hasil pengumpulan data cacat kaleng yang dilakukan dan telah dibuat menjadi check sheet dapat dilihat pada Tabel 1. Berdasarkan Table 1 data yang didapat mulai tanggal 16 Agustus 2020 sampai 15 Agustus 2020, dapat dijelaskan bahwa perusahaan pengalengan ikan dapat memproduksi sarden kaleng sebanyak 2.926.298 dan total kerusakan sebanyak 4.979. Kerusakan paling banyak pada produksi pengalengan ikan terdapat pada area seamer yaitu sebanyak 4.014 dan kerusakan yang paling sedikit pada bagian conveyor sebanyak 519. Untuk memudahkan dalam melihat jenis kerusakan yang terjadi sesuai dengan tabel 10, maka langkah selanjutnya adalah membuat diagram histogramnya. Data produk cacat tersebut disajikan dalam bentuk grafik balok yang dibagi berdasarkan jenis kerusakan.

Tabel 1. Jumlah produksi dan jumlah produk yang cacat/rusak beserta jenis kerusakannya

\begin{tabular}{|c|c|c|c|c|c|}
\hline \multirow[t]{2}{*}{ Tanggal } & \multirow{2}{*}{$\begin{array}{l}\text { Jumlah } \\
\text { Produksi }\end{array}$} & \multicolumn{3}{|c|}{ Jenis Rusak } & \multirow{2}{*}{$\begin{array}{c}\text { Jumlah } \\
\text { Rusak }\end{array}$} \\
\hline & & Rusak Seamer & $\begin{array}{c}\text { Rusak } \\
\text { Conveyor }\end{array}$ & $\begin{array}{c}\text { Rusak } \\
\text { Percobaan }\end{array}$ & \\
\hline $16 / 07 / 20$ & 110.759 & 67 & 16 & 32 & 115 \\
\hline $17 / 07 / 20$ & 145.263 & 98 & 27 & 32 & 157 \\
\hline $18 / 07 / 20$ & 141.623 & 78 & 17 & 32 & 127 \\
\hline $20 / 07 / 20$ & 98.634 & 57 & 11 & 32 & 100 \\
\hline $21 / 07 / 20$ & 125.350 & 15 & 13 & 12 & 40 \\
\hline $22 / 07 / 20$ & 148.338 & 177 & 23 & 32 & 232 \\
\hline $23 / 07 / 20$ & 148.121 & 198 & 19 & 32 & 249 \\
\hline $24 / 07 / 20$ & 105.586 & 197 & 25 & 32 & 254 \\
\hline $25 / 07 / 20$ & 45.204 & 97 & 27 & 32 & 156 \\
\hline $27 / 07 / 20$ & 120.826 & 87 & 15 & 32 & 134 \\
\hline $28 / 07 / 20$ & 159.786 & 235 & 23 & 56 & 314 \\
\hline $29 / 07 / 20$ & 33.946 & 35 & 7 & 32 & 74 \\
\hline $30 / 07 / 20$ & 121.618 & 209 & 23 & 40 & 272 \\
\hline 01/08/20 & 166.838 & 209 & 23 & 40 & 272 \\
\hline 03/08/20 & 169.720 & 317 & 23 & 40 & 380 \\
\hline 04/08/20 & 101.403 & 590 & 27 & 40 & 257 \\
\hline 05/08/20 & 90.640 & 57 & 13 & 10 & 80 \\
\hline 06/08/20 & 121.557 & 278 & 25 & 40 & 343 \\
\hline 07/08/20 & 116.448 & 117 & 25 & 40 & 182 \\
\hline 08/08/20 & 165.644 & 317 & 27 & 44 & 388 \\
\hline $10 / 08 / 20$ & 48.120 & 56 & 13 & 8 & 77 \\
\hline $11 / 08 / 20$ & 71.664 & 107 & 17 & 32 & 156 \\
\hline $12 / 08 / 20$ & 67.447 & 98 & 23 & 32 & 153 \\
\hline $13 / 08 / 20$ & 103.830 & 106 & 24 & 40 & 170 \\
\hline $14 / 08 / 20$ & 72.543 & 197 & 20 & 40 & 257 \\
\hline $15 / 08 / 20$ & 125.390 & 15 & 13 & 12 & 40 \\
\hline TOTAL & 2.926 .298 & 4.014 & 519 & 846 & 4.979 \\
\hline
\end{tabular}

Sumber: CV. Pasific Harvest 


\section{Histogram}

Setelah membuat lembar pengecekan, langkah selanjutnya adalah membuat histogram. Histogram merupakan alat untuk menunjukkan variasi data pengukuran, sehingga dapat digunakan untuk menunjukkan variasi setiap proses (Handes et al, 2013). Histogram berguna untuk mempermudah dalam membaca atau menjelaskan data dengan cepat, data tersebut perlu untuk disajikan dalam bentuk histogram yang berupa alat penyajian data secara visual berbentuk grafik balok yang memperlihatkan distribusi nilai yang diperoleh dalam bentuk angka. Histogram kerusakan kaleng dapat dilihat pada Gambar 1. Gambar 1 menunjukkan histogram yang dibuat berdasarkan tabel lembar pengecekkan. Dari gambar 1, dapat dilihat jenis kerusakan yang paling banyak terjadi pada kerusakan seamer dengan jumlah total kerusakan sebanyak 4.014 produk hal tersebut disebabkan karena mesin seamer yang sudah tua sehingga tidak bekerja secara stabil sehingga perlu dilakuakn proses pengecekan secara berkala oleh QC bagian seamer. Kerusakan terbanyak kedua rusak lecet dengan jumlah kerusakan 846 produk. Kerusakan yang paling sedikit terdapat pada kerusakan conveyor dengan jumlah kerusakan sebanyak 519 produk.

\section{Kerusakan Produk}

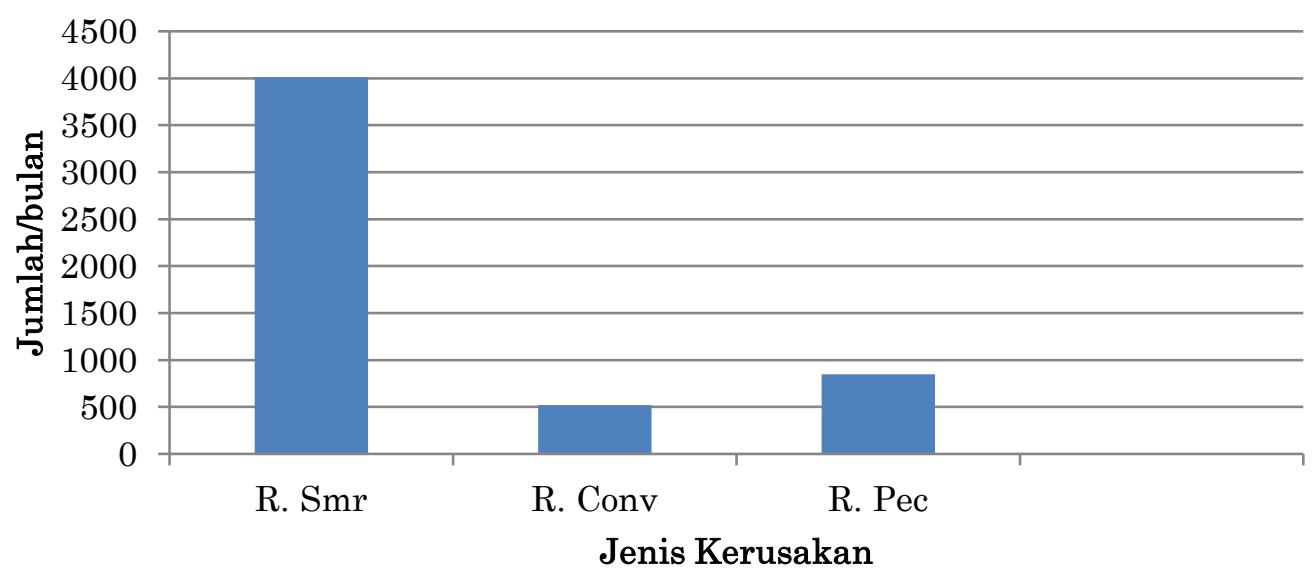

Gambar 1. Histogram jumlah kerusakan produk (R.smr: rusak seamer; R.conv: rusak conveyor; R.Pec: rusak percobaan)

\section{Peta Kendali (Control Chart)}

Peta kendali adalah sarana yang utama untuk melaksanakan metode pengendalian kualitas statistika. Peta kendali merupakan kumpulan data yang ditulis dalam bentuk grafik dan digunakan untuk membuat penilaian status pengendalian kualitas pada sebuah proses produksi (Ilham et al, 2012). Peta kendali menunjukkan adanya perubahan data dari waktu ke waktu, tetapi tidak menunjukkan penyebab penyimpangan meskipun penyimpangan tersebut akan 
terlihat pada peta kendali. Adapun langkah-langkah dalam membuat peta kendali $\mathrm{p}$ ( $p$ chart) sebagai berikut:

a. Menghitung Persentase Kerusakan

Rumus menghitung persentase kerusakan yaitu:

$\mathrm{p}=\frac{n p}{n}$

Keterangan:

$n p:$ jumlah gagal dalam sub grup

$n$ : jumlah yang diperiksa dalam sub grup

Subgrup: Hari ke-

b. Menghitung Garis Tengah

Garis tengah merupakan rata-rata kerusakan produk.

$\mathrm{CL}=\underline{p}=\frac{\Sigma n p}{\Sigma n}$

Keterangan:

$\underline{p} \quad$ : rata rata kerusakan produk

¿np : jumlah total rusak

$\Sigma n \quad$ : jumlah total yang diperiksa

c. Menghitung Batas Kendali atas

$\mathrm{UCL}=\underline{p}+3 \frac{\sqrt{\underline{\underline{p}(1-\underline{p})}}}{n}$

Keterangan:

$p$ : rata-rata kerusakan produk

$n$ : jumlah produksi

d. Menghitung Batas Kendali Bawah

$\mathrm{LCL}=\underline{p}-3 \frac{\sqrt{\underline{\underline{p}(1-\underline{p})}}}{n}$

Keterangan:

$\underline{p}$ : rata-rata kerusakan produk

$n$ : jumlah produksi 
Tabel 2. Perhitungan Persentase Kerusakan Produk

\begin{tabular}{|c|c|c|c|c|c|c|}
\hline \multirow[t]{2}{*}{ Tanggal } & \multirow{2}{*}{$\begin{array}{l}\text { Jumlah } \\
\text { Produk }\end{array}$} & \multicolumn{3}{|c|}{ Jenis Rusak } & \multirow{2}{*}{$\begin{array}{l}\text { Jumlah } \\
\text { Rusak }\end{array}$} & \multirow{2}{*}{$\begin{array}{c}\text { Proporsi } \\
\text { Kerusakan }\end{array}$} \\
\hline & & $\begin{array}{c}\text { Rusak } \\
\text { Seamer }\end{array}$ & $\begin{array}{c}\text { Rusak } \\
\text { Conveyor }\end{array}$ & $\begin{array}{c}\text { Rusak } \\
\text { Percobaan }\end{array}$ & & \\
\hline $16 / 07 / 20$ & 110.759 & 67 & 16 & 32 & 115 & 0,0010 \\
\hline $17 / 07 / 20$ & 145.263 & 98 & 27 & 32 & 157 & 0,0011 \\
\hline $18 / 07 / 20$ & 141.623 & 78 & 17 & 32 & 127 & 0,0009 \\
\hline $20 / 07 / 20$ & 98.634 & 57 & 11 & 32 & 100 & 0,0010 \\
\hline $21 / 07 / 20$ & 125.350 & 15 & 13 & 12 & 40 & 0,0003 \\
\hline $22 / 07 / 20$ & 148.338 & 177 & 23 & 32 & 232 & 0,0016 \\
\hline $23 / 07 / 20$ & 148.121 & 198 & 19 & 32 & 249 & 0,0017 \\
\hline $24 / 07 / 20$ & 105.586 & 197 & 25 & 32 & 254 & 0,0024 \\
\hline $25 / 07 / 20$ & 45.204 & 97 & 27 & 32 & 156 & 0,0035 \\
\hline $27 / 07 / 20$ & 120.826 & 87 & 15 & 32 & 134 & 0,0011 \\
\hline $28 / 07 / 20$ & 159.786 & 235 & 23 & 56 & 314 & 0,0020 \\
\hline $29 / 07 / 20$ & 33.946 & 35 & 7 & 32 & 74 & 0,0022 \\
\hline $30 / 07 / 20$ & 121.618 & 209 & 23 & 40 & 272 & 0,0022 \\
\hline $01 / 08 / 20$ & 166.838 & 209 & 23 & 40 & 272 & 0,0016 \\
\hline $03 / 08 / 20$ & 169.720 & 317 & 23 & 40 & 380 & 0,0022 \\
\hline $04 / 08 / 20$ & 101.403 & 590 & 27 & 40 & 257 & 0,0025 \\
\hline $05 / 08 / 20$ & 90.640 & 57 & 13 & 10 & 80 & 0,0009 \\
\hline $06 / 08 / 20$ & 121.557 & 278 & 25 & 40 & 343 & 0,0028 \\
\hline $07 / 08 / 20$ & 116.448 & 117 & 25 & 40 & 182 & 0,0016 \\
\hline 08/08/20 & 165.644 & 317 & 27 & 44 & 388 & 0,0023 \\
\hline $10 / 08 / 20$ & 48.120 & 56 & 13 & 8 & 77 & 0,0016 \\
\hline $11 / 08 / 20$ & 71.664 & 107 & 17 & 32 & 156 & 0,0022 \\
\hline $12 / 08 / 20$ & 67.447 & 98 & 23 & 32 & 153 & 0,0023 \\
\hline $13 / 08 / 20$ & 103.830 & 106 & 24 & 40 & 170 & 0,0016 \\
\hline $14 / 08 / 20$ & 72.543 & 197 & 20 & 40 & 257 & 0,0035 \\
\hline $15 / 08 / 20$ & 125.390 & 15 & 13 & 12 & 40 & 0,0003 \\
\hline Total & 2.926 .298 & 4.014 & 519 & 846 & 4.979 & \\
\hline
\end{tabular}


Tabel 3. Hasil Perhitungan CL, UCL, dan LCL

\begin{tabular}{ccccccc}
\hline Tanggal & Jumlah & $\begin{array}{c}\text { Jumlah } \\
\text { Produk }\end{array}$ & $\begin{array}{c}\text { Proporsi } \\
\text { Kerusakan }\end{array}$ & CL & UCL & LCL \\
\hline $16 / 07 / 20$ & 110.759 & 115 & 0,0010 & 0,002 & 0,0021 & 0,0013 \\
$17 / 07 / 20$ & 145.263 & 157 & 0,0011 & 0,002 & 0,0020 & 0,0014 \\
$18 / 07 / 20$ & 141.623 & 127 & 0,0009 & 0,002 & 0,0020 & 0,0014 \\
$20 / 07 / 20$ & 98.634 & 100 & 0,0010 & 0,002 & 0,0021 & 0,0013 \\
$21 / 07 / 20$ & 125.350 & 40 & 0,0003 & 0,002 & 0,0021 & 0,0014 \\
$22 / 07 / 20$ & 148.338 & 232 & 0,0016 & 0,002 & 0,0020 & 0,0014 \\
$23 / 07 / 20$ & 148.121 & 249 & 0,0017 & 0,002 & 0,0020 & 0,0014 \\
$24 / 07 / 20$ & 105.586 & 254 & 0,0024 & 0,002 & 0,0021 & 0,0013 \\
$25 / 07 / 20$ & 45.204 & 156 & 0,0035 & 0,002 & 0,0023 & 0,0011 \\
$27 / 07 / 20$ & 120.826 & 134 & 0,0011 & 0,002 & 0,0021 & 0,0013 \\
$28 / 07 / 20$ & 159.786 & 314 & 0,0020 & 0,002 & 0,0020 & 0,0014 \\
$29 / 07 / 20$ & 33.946 & 74 & 0,0022 & 0,002 & 0,0024 & 0,0010 \\
$30 / 07 / 20$ & 121.618 & 272 & 0,0022 & 0,002 & 0,0021 & 0,0013 \\
$01 / 08 / 20$ & 166.838 & 272 & 0,0016 & 0,002 & 0,0020 & 0,0014 \\
$03 / 08 / 20$ & 169.720 & 380 & 0,0022 & 0,002 & 0,0020 & 0,0014 \\
$04 / 08 / 20$ & 101.403 & 257 & 0,0025 & 0,002 & 0,0021 & 0,0013 \\
$05 / 08 / 20$ & 90.640 & 80 & 0,0009 & 0,002 & 0,0021 & 0,0013 \\
$06 / 08 / 20$ & 121.557 & 343 & 0,0028 & 0,002 & 0,0021 & 0,0013 \\
$07 / 08 / 20$ & 116.448 & 182 & 0,0016 & 0,002 & 0,0021 & 0,0013 \\
$08 / 08 / 20$ & 165.644 & 388 & 0,0023 & 0,002 & 0,0020 & 0,0014 \\
$10 / 08 / 20$ & 48.120 & 77 & 0,0016 & 0,002 & 0,0023 & 0,0011 \\
$11 / 08 / 20$ & 71.664 & 156 & 0,0022 & 0,002 & 0,0022 & 0,0012 \\
$12 / 08 / 20$ & 67.447 & 153 & 0,0023 & 0,002 & 0,0022 & 0,0012 \\
$13 / 08 / 20$ & 103.830 & 170 & 0,0016 & 0,002 & 0,0021 & 0,0013 \\
$14 / 08 / 20$ & 72.543 & 257 & 0,0035 & 0,002 & 0,0022 & 0,0012 \\
$15 / 08 / 20$ & 125.390 & 40 & 0,0003 & 0,002 & 0,0021 & 0,0014 \\
\hline & & & & & & \\
\hline
\end{tabular}




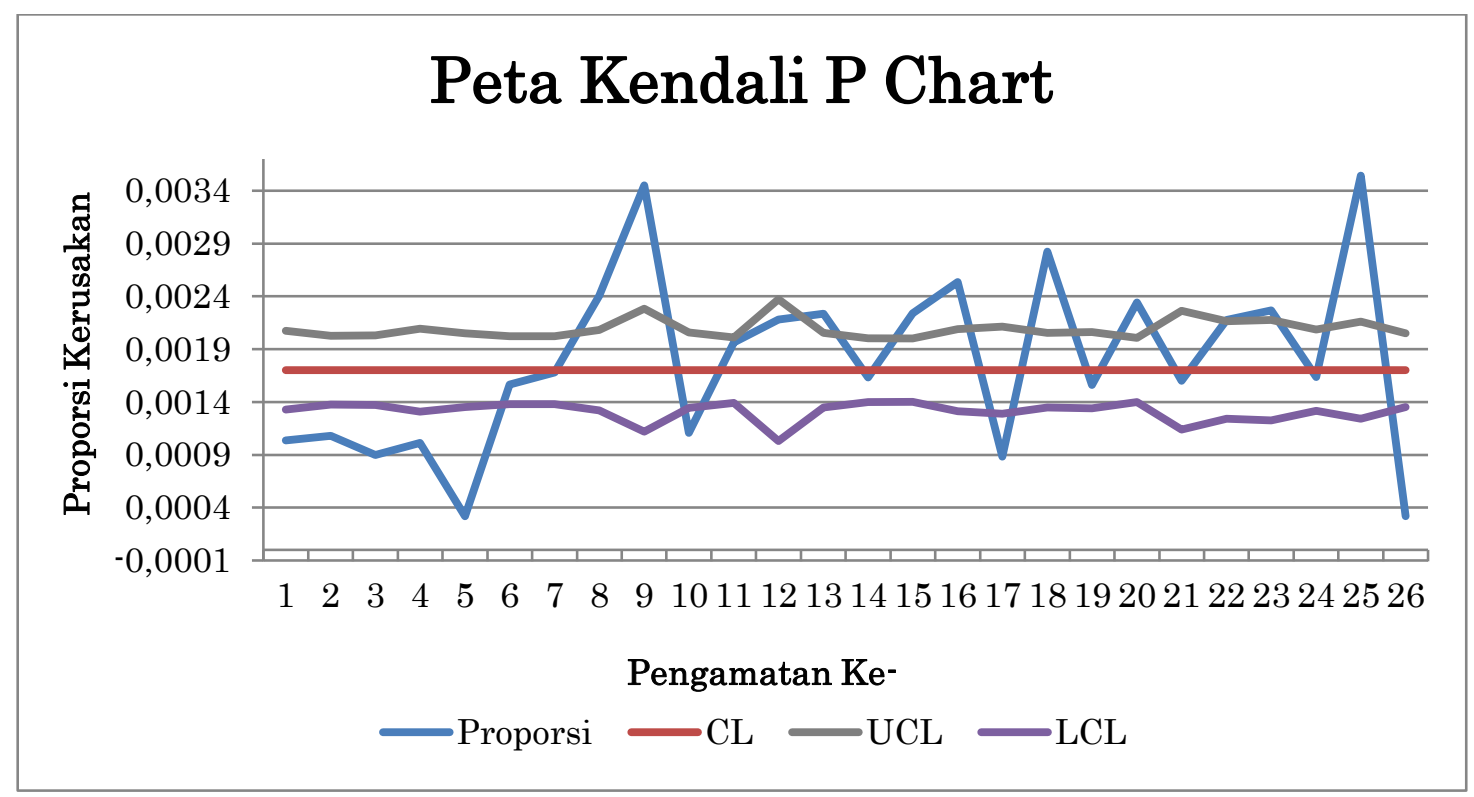

Gambar 2. Grafik Peta Kendali P

Dari hasil perhitungan nilai persentase dari setiap subgrup, nilai garis tengah (CL), nilai batas atas (UCL), dan nilai batas bawah (LCL) diketahui, maka selanjutnya dapat dibuat peta kendali $\mathrm{p}$ ( $\mathrm{chart}$ ) yang dapat dilihat pada Gambar 2. Berdasarkan gambar 2 pada peta kendali p, dapat dilihat bahwa terdapat data yang berada diluar batas kendali atas, yaitu pada titik 9, 13, 16. 19, 22 dan 25, sehingga bisa dikatakan bahwa proses tidak terkendali atau menunjukkan terdapat penyimpangan. Penyimpangan ini mengidentifikasikan bahwa masih terdapat permasalahan pada proses produksi. Penyimpangan tersebut disebabkan oleh faktor-faktor yang meliputi tenaga kerja, material, metode dan mesin. Oleh sebab itu diperlukan analisis lebih lanjut penyebab terjadinya penyimpangan yang sudah terlihat pada peta kendali $\mathrm{p}$ di atas. Selanjutnya faktor-faktor penyebab khusus ini akan dianalisis dengan menggunakan diagram sebab akibat untuk mengetahui penyebab dan penyimpangan produk pengalengan ikan (Control Chart)

\section{Diagram Sebab Akibat}

Diagram Sebab Akibat adalah suatu pendekatan terstruktur yang memungkinkan dilakukan suatu analisis lebih terperinci dalam menemukan penyebab-penyebab suatu masalah, ketidaksesuaian, dan kesenjangan yang terjadi. Diagram sebab dan akibat digunakan untuk mengidentifikasi dan menganalisis suatu proses atau situasi dan menemukan kemungkinan penyebab suatu persoalan atau masalah yang terjadi (Ratnadi \& Suprianto, 2016). Setelah mengetahui masalah utama yang paling dominan dengan menggunakan histogram. Langkah selanjutnya adalah menganalisis faktor penyebab kerusakan produk dengan menggunakan diagram tulang ikan (Fishbone diagram), sehingga 
dapat menganalisis faktor-faktor apa saja yang menjadi penyebab kerusakan produk. Diagram sebab akibat yang digunakan untuk menganalisis faktor-faktor penyebab kerusakan produk pengalengan ikan merek asahi sarden saus tomat 155 g dapat dilihat pada Gambar 3.

Berdasarkan diagram sebab akibat pada Gambar 3, diketahui bahwa faktor-faktor penyebab kerusakan kerusakan atau cacat pada produk sarden kaleng yaitu:

\section{Tenaga Kerja}

Tenaga kerja yang kurang fokus, kurang teliti dan ceroboh saat bekerja dapat mempengaruhi kualitas produk yang dihasilkan. Menurut Sucipto et al (2017) Proses produksi melibatkan manusia untuk mengubah input menjadi output. Kesalahan pekerja mempengaruhi terjadinya cacat produk. Kesalahan pekerja dipengaruhi ketidaktelitian, misal operator mesin salah melakukan setting up mesin sehingga mesin berjalan tidak stabil. Selain itu, inspektor kaleng membiarkan kaleng rusak masuk line produksi sehingga kaleng rusak terpakai. Pekerja kurang memahami SOP produksi sehingga tidak memahami tata cara produksi dan salah dalam kegiatan produksi.

2. Faktor Material

Kaleng yang digunakan oleh perusahaan sangat mempengaruhi kualitas produk yang dihasilkan. Flange penyok menyebabkan kaleng tidak dapat ditutup sehingga bocor, sedangkan curling terbuka menyebabkan drop pada tutup kaleng. Bahan kemasan yang tidak baik mempengaruhi knocked down flange yaitu flange pada kaleng rusak pada suatu bagian, kedudukan kaleng miring, dan tutup penyok (Nita, 2017)

3. Faktor Mesin

Mesin yang digunakan dalam proses pengalengan ikan ada beberapa mesin diantaranya mesin Exhaust Box, Seamer dan Retort. Mesin yang berpotensi besar menyebabkan cacat kaleng yaitu mesin seamer atau penutup kaleng sehingga perlu adanya settingan ulang pada mesin yang menyebabkan cacat kaleng. Menurut Sucipto et al (2017) Mesin seamer merupakan faktor penting keberhasilan seaming. Mesin seamer di perusahaan terkadang tidak stabil atau komponennya aus yang menyebabkan cacat kaleng.

4. Faktor Metode

Metode yang digunakan dalam produksi pengalengan ikan yaitu dari proses penerimaan bahan baku sampai dengan proses pengiriman produk akhir. Faktor metode menjadi salah satu penyebab kerusakan produk karena tidak ada instruksi kerja tertulis di beberapa area produksi yang menyebabkan karyawan kurang memahami instruksi kerja. Metode yang mempengaruhi cacat knocked down flange adalah kesalahan setting up mesin. Akibatnya mesin seamer berjalan 
tidak stabil. Kesalahan setting up mesin terjadi karena operator tidak teliti mengoperasikan mesin (Sucipto et al, 2017)

5. Faktor Lingkungan

Area kerja bagian produksi yang lembab dan panas, karena terpapar panas dari mesin produksi. Kondisi ini menyebabkan pekerja tidak nyaman sehingga konsentrasinya menurun dan memicu kesalahan atau kerusakan produk.

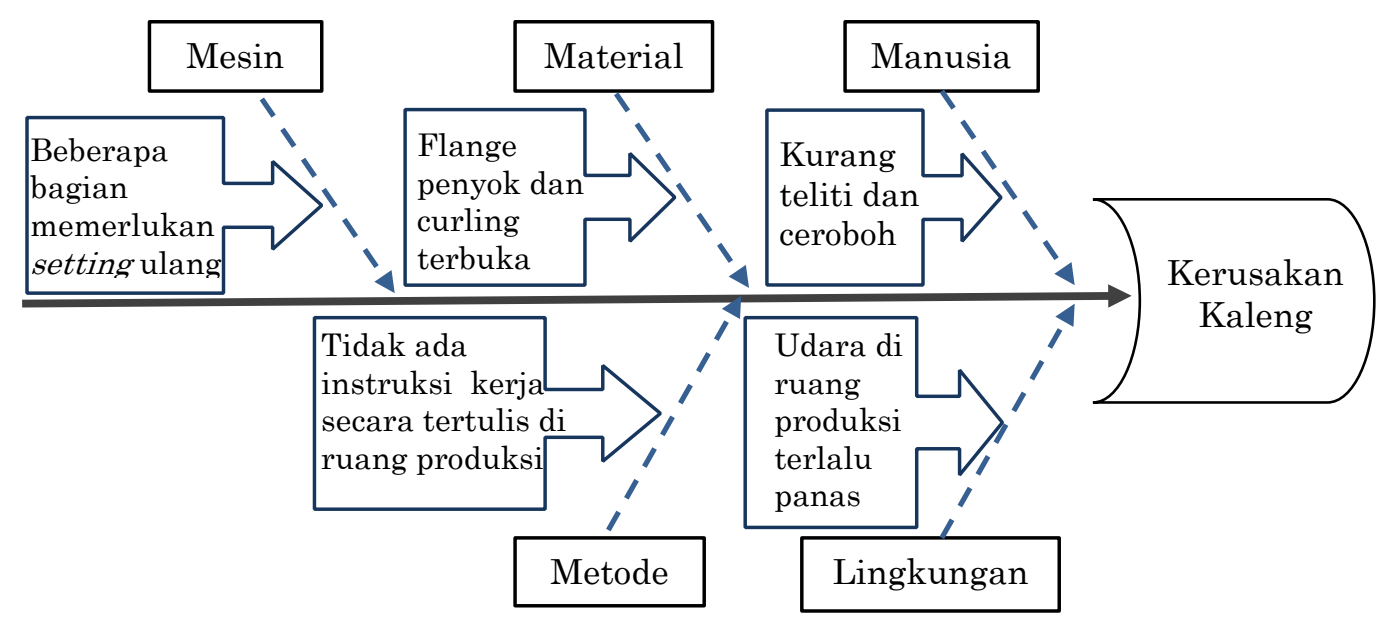

Gambar 3. Diagram Sebab Akibat

\section{KESIMPULAN}

Berdasarkan data hasil analisis menggunakan metode statistical quality control yaitu peta kendali p ( $p$ chart) diketahui masih ada kerusakan kaleng yang melebihi batas atas kendali yang berarti terdapat ketidaksesuaian atau penyimpangan dalam proses pengalengan ikan di CV. Pasific Harvest. Faktorfaktor yang mempengaruhi kerusakan atau cacat kaleng berdasarkan analisa menggunkan diagram sebab akibat yaitu faktor tenaga kerja, faktor material, faktor proses pengolahan dan faktor mesin

\section{DAFTAR PUSTAKA}

Anggraeni, D. P., Kumadji, S. \& Sunarti. 2016. Pengaruh Kualitas Produk Terhadap Kepuasan dan Loyalitas Pelanggan. Jurnal Administrasi Bisnis, 37(1)

Bakhtiar, S., Tahir, S., \& Hasni, R. A. 2013. Analisa Pengendalian Kualitas dengan Menggunakan Metode Statistical Quality Control (SQC) (Studi kasus : pada UD. Mestika Tapaktuan). Industrial Engineering Journal, 2(1), pp. $29-36$

Darsono. 2013. Analisis Pengendalian Kualitas Produksi dalam Upaya Mengendalikan Tingkat Kerusakan Produk. Jurnal Ekonomi Manajemen Akuntansi, 20(35) 
Elmas, M. S. H. 2017. Pengendalian Kualitas Dengan Menggunakan Metode Statistical Quality Control (SQC) Untuk Meminimumkan Produk Gagal Pada Toko Roti Barokah Bakery. Jurnal Penelitian Ilmu Ekonomi WIGA, Vol. 7.

Hairiyah, N., \& Riyadi, H. 2017. Analisis Pengendalian Mutu Produk Tahu Menggunakan Metode Statistical Quality Control (SQC) di UD Sari Bumi Pelaihari. In Prosiding Seminar Nasional Riset Terapan Politeknik Negeri Banjarmasin "Optimasi Hasil Riset Ilmu Pengetahuan dan Teknologi Untuk Mewujudkan Sinergi Perguruan Tinggi dan Masyarakat." Banjarmasin: Politeknik Negeri Banjarmasin.

Hairiyah, N., Amalia, R. R. \& Luliyanti, E. 2019. Statistical Quality Control (SQC) pada Produksi Roti di Aremania Bakery. Industria: Jurnal Teknologi dan Manajemen Agroindustri, 8(1), pp. 14-18. https://doi.org/10.21776/ub.industria.2019.008.01.5

Hairiyah, N., Amalia, R. R. \& Nuryati. 2020. Pengendalian Kualiatas Amplang Menggunakan Seven Tools di UD. Kelompok Melati. AGROINTEK, 14(2), pp. 249-257. https://doi.org/10.21107/agrointek.v14i2.6055

Handes, D., Susanto, K., Novita, L., \& Wajong, A. M. R. 2013. Statistical Quality Control (SQC) pada proses produksi produk "E" di PT DYN, TBK. Inasea, 14(2), 177-186.

Idris, I., Sari, R. A, Wulandari. \& Uthumporn, U. 2016. Pengendalian Kualitas Tempe dengan Metode Seven Tools. Jurnal Teknovasi, 3(1), pp. 66-80.

Ilham, M. N., Brasit, N., \& Dewi, R. S. 2012. Analisis Pengendalian Kualitas Produk dengan Menggunakan Statistical Processing Control (SPC) pada PT Bosowa Media Grafika (Tribun Timur). Skripsi. Jurusan Manajemen. Fakultas Ekonomi dan Bisnis. Universitas Hasanuddin. Makassar.

Rahayu, P. 2020. Analisis Pengendalian Kualitas Produk Menggunakan Metode Statistic Quality Control (SQC) di Plant D Divisi Curing PT. Gajah Tunggal, Tbk. Jurnal Teknik. Vol. 9. No. 1. http://dx.doi.org/10.31000/jt.v9i1.2278

Ratnadi, \& Suprianto, E. 2016. Pengendalian Kualitas Produksi Menggunakan Alat Bantu Statistik (Seven Tools) dalam Upaya Menekan Tingkat Kerusakan Produk. Indept : Industri Elektronika Penerbangan, 5(2), pp. 1018.

Rusdianto, A. S., Novijanto, N. \& Alihsany, R. Penerapan Statistical Quality Control Pada Pengolahan Kopi Robusta Cara Semi Basah. Jurnal Agrotek, $5(2)$

Sucipto., Sulistyowati, D. P. \& Anggarini, S. 2017. Pengedalian Kualitas Jamur dengan Metode Six Sigma di PT Y Pasuruhan, JawaTimur. Jurnal Teknologi dan Manajemen Agroindustri, 6(1)

Susilo, E. 2015. Variabilitas Faktor Lingkungan pada Habitat Ikan Lemuru di Selat Bali Menggunakan Data Satelit Oseanografi dan Pengukuran Insitu. Omni Akuatika, 14(20), 13-22.

Wulandari, D. A., Abida, I. W. \& Farid, A. Kualitas Mutu Bahan Mentah dan Produk Akhir Pada Unit Pengalengan Ikan Sardine Di PT. Karya Manunggal Prima Sukses Muncar Banyuwangi. Jurnal Kelautan, 2(1) 
Zecky, M. V. \& Dyah, R. 2018. Penerapan Metode Statistical Quality Control(SQC) Dalam Meminimalisir Cacat Produk Paving Block K300-T6 Di PT. Ase Gresik. JPTM, 06(03), pp. 86-92. 